\title{
Fluidity of Sarcoplasmic Reticulum Membranes Investigated with Dipyrenylpropane, an Intramolecular Excimer Probe ${ }^{\dagger}$
}

\author{
Leonor M. Almeida, Winchil L. C. Vaz, Klaas A. Zachariasse, and Vitor M. C. Madeira*
}

ABSTRACT: Intramolecular excimer formation with 1,3-di(1pyrenyl)propane was used to probe the fluidity of sarcoplasmic reticulum (SR) membranes where the probe could be incorporated (in a probe/lipid molar ratio of $1 / 2000$ or less) without inducing any detectable damage. The temperature was varied between -1 and $40^{\circ} \mathrm{C}$. The fluidity of the native SR membrane changes from $52 \mathrm{cP}$ at $40^{\circ} \mathrm{C}$ to $325 \mathrm{cP}$ at $5^{\circ} \mathrm{C}$. The native SR membranes are less fluid than liposomes prepared from total membrane lipids. The fluidity of membranes reconstituted from the SR ATPase and a total lipid extract of

$\mathbf{I}_{\mathbf{n}}$ ntramolecular excimer formation is sensitive to fluidity and has been used, mainly with 1,3-di(1-pyrenyl)propane [Py(3)Py], ${ }^{1}$ to study fluidity changes and phase transitions of synthetic phospholipid bilayers (Zachariasse et al., 1980; Melnick et al., 1981), aqueous micellar solutions (Zachariasse, 1978; Emert et al., 1979), and biological membranes (Melnick et al., 1981; Zachariasse et al., 1982). This methodology has an advantage over its counterpart based on intermolecular excimer formation, since very small probe concentrations can be employed $\left(<10^{-6} M\right)$ (Zachariasse et al., 1980, 1982). The use of low probe concentrations is possible as intramolecular excimer formation is a monomolecular process, independent of concentration (Zachariasse et al., 1980, 1982). In this manner, the formation of aggregates in viscous media such as biomembranes is avoided (Zachariasse, 1978; Galla \& Sackmann, 1974). Furthermore, perturbations of the membrane by the probe molecule are minimized.

Sarcoplasmic reticulum (SR) membranes are well characterized in their structural and functional aspects (Weber et al., 1963; Hasselbach, 1979; Tada et al., 1978). They contain one major protein, the $\left(\mathrm{Ca}^{2+}+\mathrm{Mg}^{2+}\right)$-dependent ATP phosphohydrolase (Ca-ATPase), associated intrinsically with the membrane lipids (Weber et al., 1963; Martonosi et al., 1971). Its simplicity and uniformity make the SR membrane system particularly attractive as a model for biochemical and biophysical studies.

The activity of the SR ATPase has been shown to be critically dependent upon the presence of lipid (Weber et al., 1963; Warren et al., 1974; Bennett et al., 1980). Thus, $\mathrm{Ca}^{2+}$ transport across the SR membrane and the associated transduction between the osmotic energy of $\mathrm{Ca}^{2+}$ gradients and the chemical energy of ATP may be modulated by lipid-protein interactions in the membrane. These lipid-protein interactions can be reflected in physical properties of the membrane such as fluidity. It is therefore of interest to investigate the SR membranes with probe molecules such as Py(3)Py, which can directly report on this parameter.

\footnotetext{
${ }^{\dagger}$ From the Centro de Biologia Celular, Departamento de Zoologia, Universidade de Coimbra, 3049 Coimbra Codex, Portugal (L.M.A. and V.M.C.M.), and the Max-Planck-Institut für Biophysikalische Chemie, D-3400 Göttingen, West Germany (W.L.C.V. and K.A.Z.). Received February 22, 1982. This study was supported by grants from I.N.I.C., J.N.I.C.T., and the Calouste Gulbenkian Foundation.
}

the SR depends on the lipid/protein molar ratio and sharply decreases when this ratio becomes lower than 44 , for all temperatures studied. This is in accord with literature reports describing the occurrence of approximately 30 lipid molecules around the Ca-ATPase molecule in the SR membrane. Arrhenius plots of the excimer to monomer fluorescence intensity ratio in native and reconstituted SR membranes display a break at about $20^{\circ} \mathrm{C}$ which is not observed when the lipid/ protein ratio is lower than 44 . This break is interpreted as being a characteristic of the lipid portion of the membrane.

Excimer Kinetics. Intramolecular excimer formation, due to association of an excited and an unexcited aromatic group incorporated in the same molecule, can be described by the excimer to monomer fluorescence quantum yield ratio, $\phi^{\prime} / \phi$, which is proportional to the fluorescence intensity ratio, $I^{\prime} / I$ (Zachariasse et al., 1978, 1980).

$$
\frac{I^{\prime}}{I} \approx \frac{\phi^{\prime}}{\phi}=\frac{K_{\mathrm{f}}^{\prime}}{K_{\mathrm{f}}} \frac{K_{\mathrm{a}}}{K_{\mathrm{d}}+1 / \tau_{0}^{\prime}}
$$

Here, $K_{\mathrm{f}}{ }^{\prime}, K_{\mathrm{f}}, K_{\mathrm{a}}$, and $K_{\mathrm{d}}$ are the rate constants for excimer fluorescence, monomer fluorescence, excimer formation, and excimer dissociation, respectively, and $\tau_{0}{ }^{\prime}$ is the excimer lifetime in the absence of $K_{\mathrm{d}}$. At low temperatures, or at sufficiently high local viscosities, as in our experimental conditions, $K_{\mathrm{d}} \ll<1 / \tau_{0}^{\prime}$ (Zachariasse et al., 1980), and eq 1 assumes a simplified form:

$$
\frac{I^{\prime}}{I} \approx \frac{\phi^{\prime}}{\phi}=\frac{K_{\mathrm{f}}^{\prime}}{K_{\mathrm{f}}} K_{\mathrm{a}} \tau_{0}{ }^{\prime}
$$

Therefore, under these conditions, the fluorescence intensity ratio $I^{\prime} / I$ is primarily determined by the rate constant of excimer formation, $K_{\mathrm{a}}$, since the radiative rate constants and $\tau_{0}{ }^{\prime}$ have been found to be essentially independent of temperature (Zachariasse et al., 1980). Since $I^{\prime} / I$ of Py(3)Py has been shown to increase with fluidity in highly viscous media (Melnick et al., 1981; Zachariasse, 1978), the technique is suitable to determine the fluidity of the probe environment in media such as biomembranes. It should be noted that the term fluidity is used here in an operational manner ( $\mathrm{Za}$ chariasse et al., 1982).

\section{Materials and Methods}

Fragmented sarcoplasmic reticulum was prepared as described elsewhere (Madeira \& Antunes-Madeira, 1976). The protein concentrations were normally determined by the biuret method (Gornall et al., 1949). Some preparations were also

\footnotetext{
${ }^{1}$ Abbreviations: ATP, adenosine 5'-triphosphate; $\mathrm{Ca}$-ATPase, $\mathrm{CCa}^{2+}$ $+\mathrm{Mg}^{2+}$ )-dependent ATP phosphohydrolase; DMPC, dimyristoylphosphatidylcholine; EGTA, ethylene glycol bis( $\beta$-aminoethyl ether)$N, N, N^{\prime}, N^{\prime}$-tetraacetic acid; Py(3)Py, 1,3-di(1-pyrenyl)propane; SR, sarcoplasmic reticulum; Tris, tris(hydroxymethyl)aminomethane; NaDodSO $_{4}$, sodium dodecyl sulfate.
} 
assayed by the Lowry procedure (Lowry et al., 1951), calibrated by the biuret analysis.

The Ca-ATPase was purified by gel filtration on a Sephadex G100 column $(2.5 \times 90 \mathrm{~cm})$ loaded with $200 \mathrm{mg}$ of membrane protein solubilized with $3 \%$ Triton $\mathrm{X}-100$. The column was eluted with a solution containing $0.2 \mathrm{M} \mathrm{KCl}, 1 \mathrm{mM} \mathrm{MgCl}_{2}$, $10 \mu \mathrm{M}$ protease inhibitor (phenylmethanesulfonyl fluoride), and $10 \mathrm{mM}$ Tris-maleate, $\mathrm{pH}$ 7.0. The turbid fraction eluted in the void volume was saved. This fraction contained membranous material free from proteins other than the Ca-ATPase enzyme, as judged by sodium dodecyl sulfate (NaDod$\mathrm{SO}_{4}$ )-polyacrylamide gel electrophoresis (Weber \& Osborn, 1969). The membranes were centrifuged at $200000 \mathrm{~g}$ for 40 min and resuspended in the same buffer.

Lipids were extracted, and the individual lipid classes were purified by preparative thin-layer chromatography, as previously described (Madeira \& Antunes-Madeira, 1976). The phospholipids were quantitated by measuring the amount of inorganic phosphate (Bartlett, 1959) after hydrolysis of the extracts at $180^{\circ} \mathrm{C}$ in $70 \% \mathrm{HClO}_{4}$ (Böttcher et al., 1961).

Liposomes were prepared by vortexing a mixture of $2.7 \mathrm{mg}$ of lipids with $5 \mathrm{~mL}$ of a buffer solution containing $0.1 \mathrm{M} \mathrm{KCl}$ and $5 \mathrm{mM}$ Tris- $\mathrm{HCl}, \mathrm{pH} 7.0$, for $2 \mathrm{~min}$. The mixture was then briefly sonicated in a water bath to disperse large lipid aggregates.

Reconstituted systems were prepared with the purified Ca-ATPase and lipids by the cholate dialysis procedure (Racker, 1972). Enzyme aliquots were mixed with clear solutions of lipids in cholate, in a buffer system containing 0.1 $\mathrm{M} \mathrm{KCl}, 5 \mathrm{mM} \mathrm{MgCl}, 10 \mu \mathrm{M}$ protease inhibitor, and $50 \mathrm{mM}$ Tris- $\mathrm{HCl}, \mathrm{pH} \mathrm{8.0.} \mathrm{The} \mathrm{cholate} \mathrm{to} \mathrm{lipid} \mathrm{ratio,} \mathrm{by} \mathrm{weight,} \mathrm{was}$ 0.64 , in $1 \mathrm{~mL}$ of reaction mixture. The mixtures were incubated at $4^{\circ} \mathrm{C}$ for $30 \mathrm{~min}$. The suspensions were then exhaustively dialyzed for 4 days at $4^{\circ} \mathrm{C}$ against buffer without cholate which was changed 3 times a day. The last two dialyses were done in the presence of XAD-2 (BDH) resin in the dialysis buffer.

Partially delipidated membranes were obtained by treatment with phospholipase $\mathrm{A}_{2}(0.5 \mu \mathrm{g} / \mathrm{mg}$ of protein $)$ at $30^{\circ} \mathrm{C}$ in media containing $0.1 \mathrm{M} \mathrm{KCl}, 2 \mathrm{mM} \mathrm{CaCl}_{2}$, and $20 \mathrm{mM}$ Tris-maleate, $\mathrm{pH}$ 7.0. The reaction was terminated by removing aliquots which were mixed with ice-cold $10 \mathrm{mM}$ EGTA, pH 7.0. The suspensions were mixed with buffer containing $5 \%$ fatty acid free bovine serum albumin and centrifuged at $200000 \mathrm{~g}$ for $30 \mathrm{~min}$. The pellets were then rinsed with buffer without albumin and suspended in $1.5 \mathrm{~mL}$ of the same buffer.

The incorporation of the probe was carried out by adding aliquots of an ethanolic solution of dipyrenylpropane $\left(5 \times 10^{-5}\right.$ $\mathrm{M})$ to the membrane or lipid suspensions $(0.54 \mathrm{mg}$ of phospholipid $/ \mathrm{mL}$ ), so that the final probe concentration was less than $5 \times 10^{-7} \mathrm{M}$. The mixtures were initially vigorously vortexed for $10 \mathrm{~s}$ at room temperature and then incubated at $4^{\circ} \mathrm{C}$ for $18 \mathrm{~h}$ under gentle stirring. Blanks, always prepared under identical conditions, served as controls for the fluorometric measurements. These measurements were carried out with a Perkin-Elmer spectrofluorometer, Model MPF-3, provided with a thermostated cell holder. The excitation wavelength was $330 \mathrm{~nm}$ (4-nm excitation and 6-nm emission slits). The excimer to monomer fluorescence intensity ratio was calculated from the $490 \mathrm{~nm}$ to $378 \mathrm{~nm}$ signal ratio $\left(I^{\prime} / I\right)$. These measurements were always corrected for the contribution due to light scattering by using the blank.

The viscosity of liquid paraffin (Merck, Uvasol, batch 6195354 , used as received) was determined with a thermo-

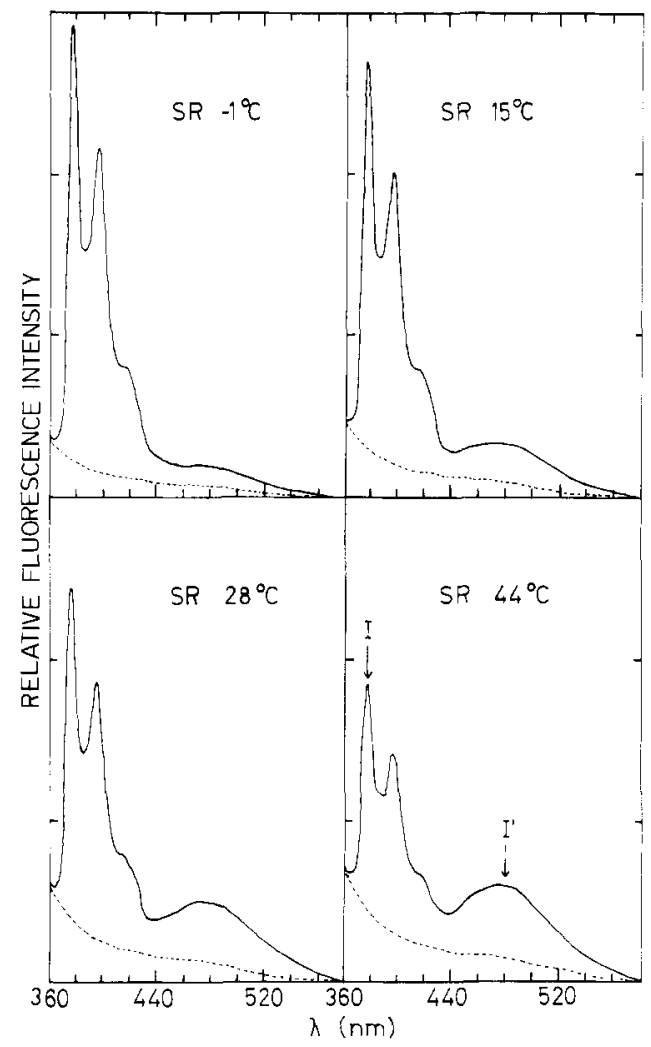

FIGURE 1: Fluorescence spectra of 1,3-di(1-pyrenyl)propane. The probe $\left(5 \times 10^{-7} \mathrm{M}\right)$ was added to sarcoplasmic reticulum suspensions in a buffer solution $(0.1 \mathrm{M} \mathrm{KCl}$ and $5 \mathrm{mM}$ Tris, $\mathrm{pH} \mathrm{7.0)}$ as described under Materials and Methods. The spectra were recorded after 18 $h$ of incubation at $4{ }^{\circ} \mathrm{C}$. Scatter of the suspensions without probe is shown by the dashed traces.

stated Hoppler viscometer at the desired temperatures. The density of paraffin was measured with a pycnometer (Connors, 1967). $\mathrm{Ca}^{2+}$ uptake was estimated from the rate of ATP hydrolysis in the presence of oxalate $\left(\mathrm{Ca}^{2+}\right.$ trapping agent), as previously described (Madeira, 1978). The ATP splitting capacity of the preparations was measured after membrane disruption with detergent to uncouple ATP hydrolysis from $\mathrm{Ca}^{2+}$ accumulation. The activity was measured by monitoring the proton production due to ATP hydrolysis, as described previously (Madeira, 1978).

\section{Results and Discussion}

Fluorescence Spectra of Dipyrenylpropane. The fluorescence spectra of the probe molecule Py(3)Py incorporated into SR membranes consist of contributions from both monomer and excimer emission, as seen in Figure 1. The spectra are completely reproducible in different preparations of the SR membrane. Also, identical results are obtained with different dilutions of the probe molecule in the membrane suspensions. The occurrence of intermolecular excimer formation can therefore be excluded.

When the temperature is raised from -1 to $40{ }^{\circ} \mathrm{C}$, the excimer to monomer fluorescence intensity ratio, $I^{\prime} / I$, increases from a value of 0.040 at $-1{ }^{\circ} \mathrm{C}$ to 0.263 at $40^{\circ} \mathrm{C}$. This ratio (see eq 2) can report the fluidity of the probe environment, here in the SR membrane.

Time Dependence of Probe Incorporation and Membrane Integrity. The time dependence of probe incorporation into SR membranes and into liposomes prepared from total SR membrane lipids is shown in Figure 2. It appears that a stationary state is achieved more rapidly with the liposomes than with the native SR membranes. At any rate, after about $18 \mathrm{~h}$ of incubation at $4{ }^{\circ} \mathrm{C}$, the value of $I^{\prime} / I$ has reached an 


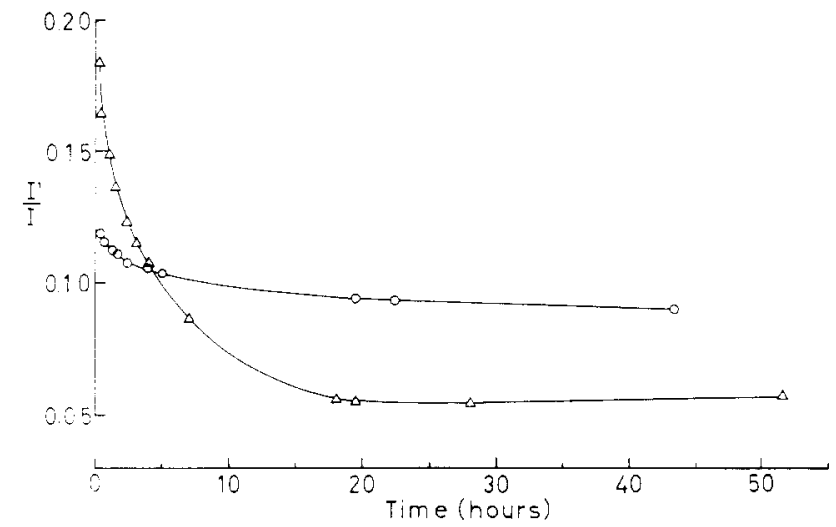

FIGURE 2: Time dependence of the incorporation of 1,3-di(1-pyrenyl)propane into the sarcoplasmic reticulum membranes. The probe was added as an ethanolic solution to aqueous suspensions of sarcoplasmic reticulum membranes $(\Delta)$ or to liposomes of total membrane lipids (O), in a probe/lipid molar ratio of $1 / 2000$. The incubation was carried out at $4{ }^{\circ} \mathrm{C}$ under gentle stirring.

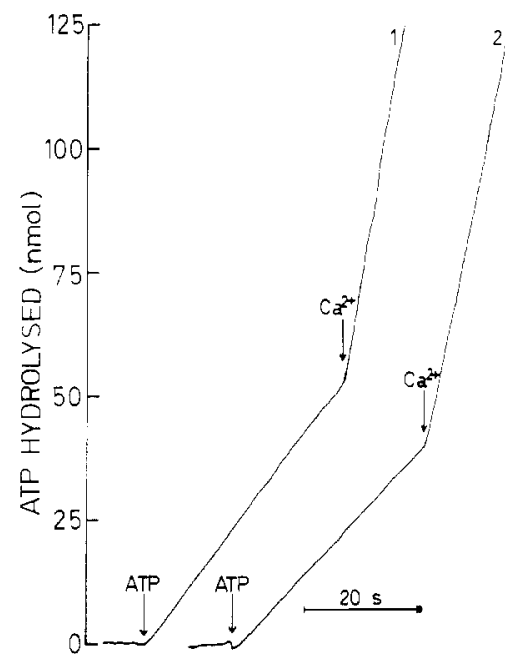

FIGURE 3: ATP hydrolysis catalyzed by native membranes (1) and by membranes with incorporated 1,3-di(1-pyrenyl)propane (2). The reactions were carried out at $27^{\circ} \mathrm{C}$ in $2.5 \mathrm{~mL}$ of medium (150 mM $\mathrm{KCl}, 5 \mathrm{mM} \mathrm{MgCl}$, and $5 \mathrm{mM}$ Tris, $\mathrm{pH} 6.9$ ) and $0.45 \mathrm{mg}$ of membrane protein. The membranes were disrupted by adding $0.08 \%$ Triton $X-1001$ min before the assay, which was initiated by adding 0.44 mM MgATP. $\mathrm{CaCl}_{2}(0.1 \mathrm{mM})$ was added as indicated. The reaction was monitored by recording the production of protons arising from ATP splitting.

almost constant value in both cases. An incubation period of $18 \mathrm{~h}$ was therefore maintained for all preparations. Since such a relatively long time was necessary before the membrane system could be measured, possible damage to the membrane integrity, which would result in inactivation of the Ca-ATPase enzyme, was examined.

Figure 3 shows that the ATP hydrolytic capacity of the enzyme in the presence of Triton X-100 is only slightly altered after addition of the probe. It is still sensitive to $\mathrm{Ca}^{2+}$ activation. Furthermore, the integrity of the membrane is maintained as judged by the capacity of the vesicles to accumulate $\mathrm{Ca}^{2+}$. This can be inferred from the results in Figure 4 , where it is shown that the ATP splitting activity sharply decreases, assuming a very low rate, when the added $\mathrm{Ca}^{2+}$ has been taken up. SR vesicles damaged by the action of detergents, mechanical stress, or sonication are unable to accumulate $\mathrm{Ca}^{2+}$, and ATP hydrolysis proceeds to complete exhaustion of ATP at a constant and very high rate (Carvalho \& Madeira, 1974). It is therefore concluded that neither the presence of the probe in the membrane nor the incubation

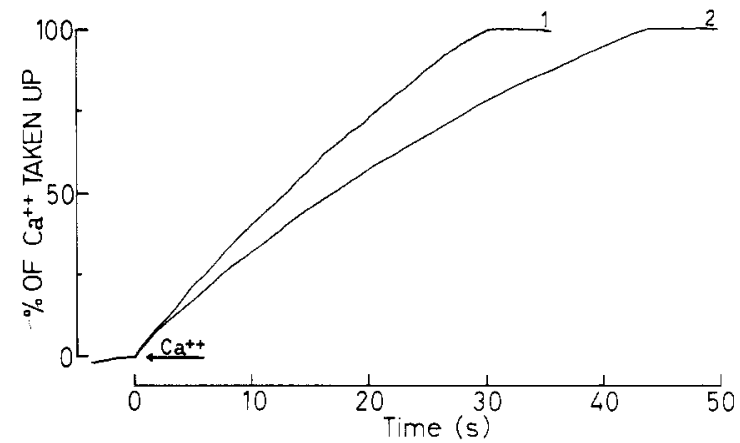

FIGURE 4: $\mathrm{Ca}^{2+}$ uptake by native sarcoplasmic reticulum membranes (1) and by SR membranes treated with 1,3-di(1-pyrenyl)propane (2). The experimental conditions were similar to those described in the legend of Figure 3, except that $5 \mathrm{mM}$ potassium oxalate was included and Triton X-100 was absent. The rate of $\mathrm{Ca}^{2+}$ translocation was estimated from ATP hydrolysis monitored by a potentiometric technique. This could be done since the ATP hydrolysis before $\mathrm{Ca}^{2+}$ addition, as indicated, can be neglected.

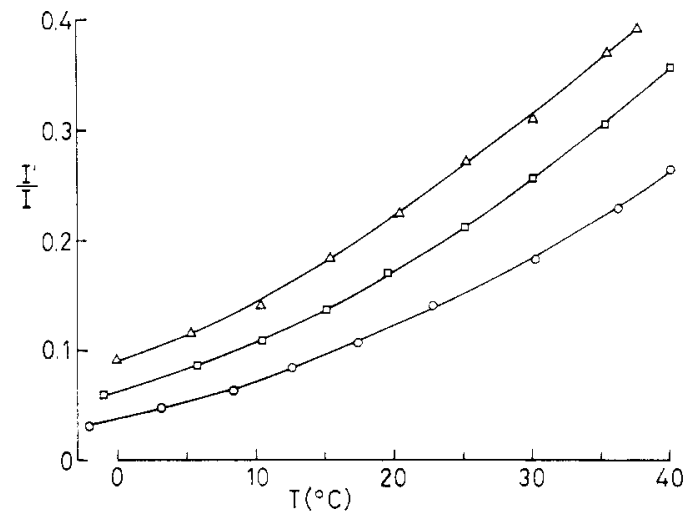

FIGURE 5: Excimer to monomer fluorescence intensity ratio, $I^{\prime} / I$, of 1,3-di(1-pyrenyl)propane in various media as a function of temperature. The probe was incorporated into native sarcoplasmic reticulum $(0)$ liposomes of total membrane lipid (ㅁ), and liposomes of the membrane phosphatidylcholine fraction $(\Delta)$.

period of $18 \mathrm{~h}$ induces significant membrane damage or enzyme inactivation.

Probe Location. NMR experiments based on ring current effects have produced evidence, in the case of pyrene in phosphatidylcholine bilayers, that this probe molecule is predominantly located in the central methylene region of the aliphatic chains, away from the polar head groups of the phospholipids (Podo \& Blasie, 1977).

Further, a recent study (Zachariasse et al., 1982) indicates that probe molecules such as Py(3)Py are located inside the membrane, not at the aqueous interface but also not in a pure alkane-chain environment. This is deduced from the local polarity and polarizability reported by the probes. The fact remains, however, that the location of the probe molecule in the membrane is not exactly known.

Intramolecular Excimer Formation in SR Membranes and Liposomes. Over the whole temperature range from -1 to 40 ${ }^{\circ} \mathrm{C}$, the value of $I^{\prime} / I$, and, therefore, the fluidity, is larger in the liposomes of total membrane lipids than in the native SR membranes (Figure 5). Further, the $I^{\prime} / I$ value of the probe in liposomes of the pure SR membrane phosphatidylcholines is again larger than in the two other membrane systems. Thus, as an example, at $37^{\circ} \mathrm{C}$, the excimer to monomer fluorescence intensity ratio of the probe molecule in liposomes of the total SR membrane lipids and of the membrane phosphatidylcholine fraction is, respectively, 1.37 and 1.63 times as large as in intact SR membranes. This means that the fluidity of the liposomes of pure SR membrane phosphatidylcholines becomes smaller 


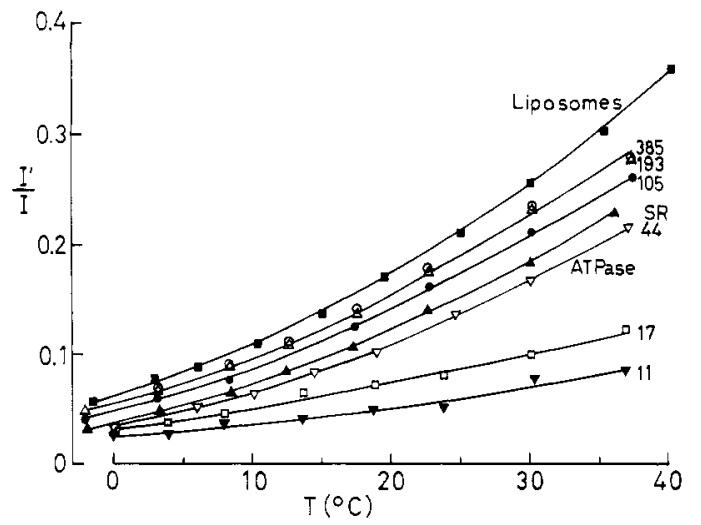

FIGURE 6: Excimer to monomer fluorescence intensity ratio, $I^{\prime} / I$, of 1,3-di(1-pyrenyl)propane in various membrane systems. The probe was incorporated into membranes with different lipid/protein molar ratios, obtained either by addition of excess lipid followed by reconstitution or by phospholipase $\mathrm{A}_{2}$ treatment of purified $\mathrm{Ca}$-ATPase membranes. The numbers beside the traces indicate the lipid/protein molar ratio. The trace ( $(\mathbf{D})$ refers to liposomes prepared from the total lipid extract, whereas the trace $(\nabla)$ is for native purified ATPase (lipid/protein molar ratio of 44 ).

because of the presence of the phosphatidylethanolamines and the other minor lipids present in the native SR membrane. Also, the presence of the proteins, mainly the Ca-ATPase, in the intact SR membrane leads to a further decrease of the fluidity.

In none of the three membrane systems presented in Figure 5 were discontinuities in the plots of the excimer to monomer fluorescence intensity ratio, $I^{\prime} / I$, vs. temperature observed. In contrast, phase transitions occurring in bilayers and vesicles of phosphatidylcholines have been clearly detected as sharp discontinuities in the plots of $I^{\prime} / I$ vs. the reciprocal of the absolute temperature, using the same probe molecule, dipyrenylpropane (Zachariasse et al., 1980). It is therefore concluded that large changes in membrane fluidity such as those that occur at phase transitions and/or phase separations do not occur in these membrane systems.

Influence of the Lipid/Protein Molar Ratio in Reconstituted Systems. Reconstituted systems having different lipid/protein molar ratios were prepared by incorporation of excess lipid in the SR membranes or by lipid release from SR membranes following phospholipase $A_{2}$ treatment. In this way, a series of systems with values of the lipid/protein molar ratio both larger and smaller than the value in the native SR membrane were obtained.

Over the whole temperature range between -1 and $40^{\circ} \mathrm{C}$, the excimer to monomer fluorescence intensity ratio, $I^{\prime} / I$, of $\mathrm{Py}(3) \mathrm{Py}$, and thus the fluidity around the probe molecule, becomes larger with increasing lipid/protein ratio (Figure 6). The largest values for $I^{\prime} / I$ is obtained for liposomes prepared from the total lipid fraction of the SR membrane. The $I^{\prime} / I$ values for the native SR membrane at the various temperatures are slightly larger than those for native purified ATPase, which has a lipid/protein molar ratio of 44 . This corresponds to a value of the lipid/protein ratio for native SR membranes that is somewhat lower than the literature values of around 90 (Bennett et al., 1980; Martonosi, 1968; Mac Lennan, 1970; Meissner et al., 1973). However, the values depend on the method used for protein determination. In our hands, the Lowry method, when not corrected by reference to the biuret procedure, gives figures similar to those currently reported (lipid/protein ratios of about 90 ).

Values of the excimer to monomer fluorescence intensity ratio, $I^{\prime} / I$, of the probe molecule taken from Figure 6 are

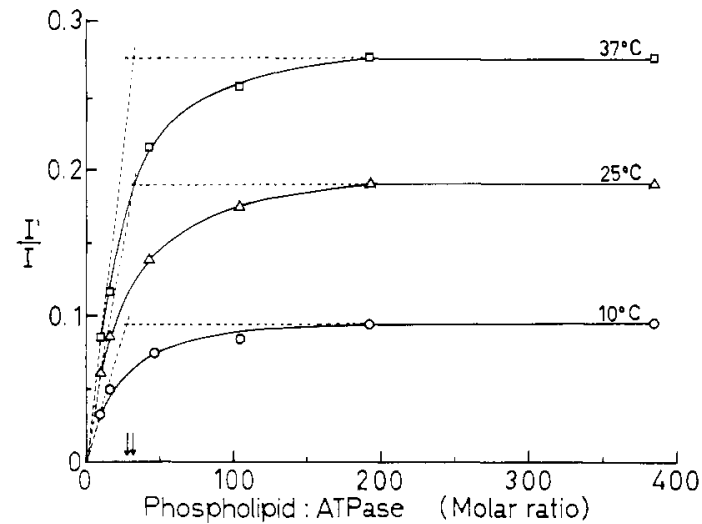

FIGURE 7: Intramolecular excimer formation of 1,3-di(1-pyrenyl)propane incorporated in different membrane systems as a function of the lipid to protein molar ratio. Curves are shown for measurements at 10,25 , and $37^{\circ} \mathrm{C}$. The tangents to the initial and final portions of the curves intersect at points corresponding to a lipid to protein molar ratio of about 30 .

presented in Figure 7, as a function of the lipid/protein molar ratio for three representative temperatures, 10,25 , and $37^{\circ} \mathrm{C}$. It is clear that the value of $I^{\prime} / I$ changes sharply with the lipid/protein molar ratio when this ratio becomes lower than 44 , whereas $I^{\prime} / I$ increases more slowly above this value. For lipid/protein ratios greater than about 100 , the changes in $I^{\prime} / I$ are small. Because of the direct relation between the value of $I^{\prime} / I$ and the fluidity of the probe surroundings (eq 2), the curves in Figure 7 depict the variation of membrane fluidity as a function of the lipid/protein molar ratio. Tangents to the initial and final portions of the curves in Figure 7 intersect at a lipid/protein molar ratio of about 30 , for all temperatures studied. It is of interest to note that this value of about 30 has been taken as the number of lipid molecules which interact directly with the Ca-ATPase enzyme in a tight layer, the so-called "lipid annulus" (Bennett et al., 1980; Hesketh et al., 1976; Metcalfe et al., 1976; Le Maire et al., 1976).

At lipid/protein molar ratios below 30, the probe molecule $\mathrm{Py}$ (3)Py can only be solubilized in the boundary around each ATPase molecule, a region of the membrane which is thought to be relatively rigid because of the lipid/protein interactions with the ATPase (Bennett et al., 1980). As the lipid/protein molar ratio increases, the probe finds itself more and more among lipids that are not so tightly associated with the protein. For lipid/protein ratios higher than 193, the fluidity of the probe surroundings is practically constant. For still larger values of this ratio, up to the liposomes of total SR membrane lipids (lipid to protein molar ratio of infinity), the fluidity increases only very slightly. A still lower fluidity, as compared to the liposomes of total SR membrane lipids, is observed for membrane systems with lipid/protein molar ratios between 44 and 193. This may suggest that the lipid/protein interactions promoted by the Ca-ATPase protein extend somewhat outside the first shell of 30 tightly bound lipid molecules. Clearly, however, the lipid-protein interactions outside the lipid surrounding the Ca-ATPase are relatively weak, exerting only a small effect on the membrane fluidity.

Arrhenius Plots for Excimer Formation in SR Membrane Systems. Arrhenius plots of SR ATPase activity display a discontinuity at temperatures around $20^{\circ} \mathrm{C}$ (Hesketh et al., 1976; Madeira et al., 1974; Inesi et al., 1973; Martonosi, 1974; Davis et al., 1976; Anzai et al., 1978). This has at first been interpreted as being due to a phase transition in the membrane lipids (Inesi et al., 1973). Later it was concluded from measurements using differential scanning calorimetry (Martonosi, 1974) and X-ray diffraction (Davis et al., 1976) that 


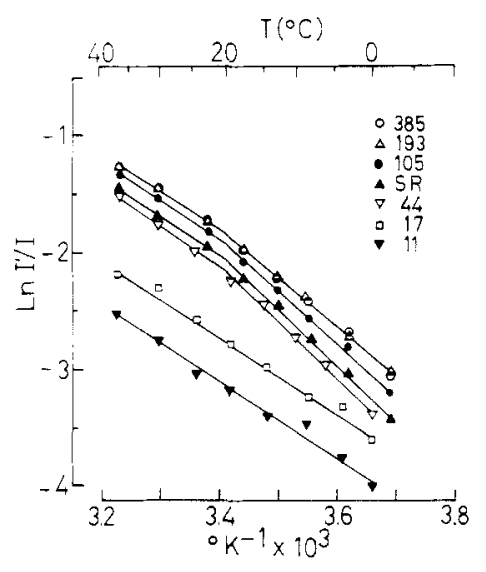

FIGURE 8: Arrhenius plots for excimer formation of 1,3-di(1-pyrenyl)propane incorporated in membrane systems with different lipid to protein molar ratios, as indicated. Trace $(\boldsymbol{\Delta})$ refers to sarcoplasmic reticulum membranes and trace $(\nabla)$ to purified ATPase (molar ratio of 44).

these breaks "probably do not reflect the thermotropic transition of membrane lipids from the gel phase to the liquidcrystalline phase (Martonosi, 1974)". Alternatively, the break in the Arrhenius plots was attributed to a change in the conformation of the ATPase molecule, still surrounded by fluid lipids, at the temperature where the break is observed (Anzai et al., 1978). Recently, it was shown that the effect of pressure presents a critical test for the involvement of lipids in discontinuities of Arrhenius plots (Heremans \& Wuytack, 1980). Also, it was demonstrated that the discontinuities coincide with the temperatures of structural perturbations of nonionic detergents used for reactivation of ATPase (Dean \& Suárez, 1981). For investigation of whether similar phenomena are reported by the Py(3)Py probe in SR membranes or membranes reconstituted with excess lipid, the $I^{\prime} / I$ data from Figure 6 are presented as Arrhenius plots in Figure 8. It is seen that the shape of the plot depends on the lipid/protein molar ratio. The plots can only be presented by a single straight line for the two systems with lipid/protein molar ratios lower than 44. All the other curves, including the one for the native SR membranes, can be resolved into two straight lines, intersecting at about $20^{\circ} \mathrm{C}$.

The apparent activation energies, $E_{\mathrm{a}}$, derived from the slopes above and below this temperature, are given in Table I. These activation energies apply to the excimer formation step with rate constant $K_{\mathrm{a}}$ (eq 2). Above $20^{\circ} \mathrm{C}$, the slope of the Arrhenius plot is found to be essentially independent of the lipid/protein molar ratio, giving in all cases activation energies of $27 \pm 1 \mathrm{~kJ} / \mathrm{mol}$. For the intact SR membranes, the same value is obtained, $28 \mathrm{~kJ} / \mathrm{mol}$ (Table I). This value is similar to the $E_{\mathrm{a}}$ value of $27 \mathrm{~kJ} / \mathrm{mol}$ obtained in aqueous micellar solutions of sodium dodecyl sulfate (Zachariasse et al., 1980). For multibilayers and vesicles of dimyristoylphosphatidylcholine (DMPC) and for human erythrocyte ghost membranes, larger values for the activation energy have been obtained, 35 $\mathrm{kJ} / \mathrm{mol}$ (above the main phase transition temperature at 23.9 ${ }^{\circ} \mathrm{C}$ ) (Zachariasse et al., 1980) and $37 \mathrm{~kJ} / \mathrm{mol}$ (Zachariasse et al., 1982), respectively (Table I).

Below $20^{\circ} \mathrm{C}$, the slope of the Arrhenius plots of $I^{\prime} / I$ is larger than the slope above this temperature, except for the systems with lipid/protein molar ratios of 17 and 11. The value of $E_{a}$, derived from the plots below $20^{\circ} \mathrm{C}$, increases with the lipid/protein molar ratio, from 35 to $41 \mathrm{~kJ} / \mathrm{mol}$ for lipid/ATPase molar ratios between 385 and 44 . The value for native sarcoplasmic reticulum membranes, $E_{\mathrm{a}}=40 \mathrm{~kJ} / \mathrm{mol}$, falls between those for the systems with lipid/protein molar ratios of
Table I: Activation Energies (in $\mathrm{kJ} / \mathrm{mol}$ ) for Excimer Formation of 1,3-Di(1-pyrenyl)propane in Various Reconstituted and Native Sarcoplasmic Reticulum Membrane Systems above and below $20^{\circ} \mathrm{C}^{a}$

\begin{tabular}{|c|c|c|}
\hline & $E_{\mathrm{a}}\left(T>20^{\circ} \mathrm{C}\right)$ & $E_{\mathbf{a}}\left(T<20^{\circ} \mathrm{C}\right)$ \\
\hline \multicolumn{3}{|l|}{ lipid/SR ATPase molar ratio } \\
\hline 385 & 27 & 35 \\
\hline 193 & 27 & 35 \\
\hline 105 & 28 & 38 \\
\hline 44 & 26 & 41 \\
\hline $17^{b}$ & 27 & 27 \\
\hline $11^{b}$ & 27 & 27 \\
\hline SR membrane & 28 & 40 \\
\hline $\begin{array}{l}\text { DMPC multibilayers and } \\
\text { vesicles } s^{c}\end{array}$ & $35\left(T>23.9^{\circ} \mathrm{C}\right)$ & $43\left(T<23.9^{\circ} \mathrm{C}\right)$ \\
\hline $\begin{array}{l}\mathrm{NaDodSO}_{4} \text { aqueous } \\
\text { micellar solution } \\
(0.1 \mathrm{M})^{b, c}\end{array}$ & 27 & 27 \\
\hline $\begin{array}{l}\text { human ery throcy te ghost } \\
\text { membranes } b, d\end{array}$ & 37 & 37 \\
\hline
\end{tabular}

${ }^{a}$ See the text and Figure 8. Also included, in the lower part of the table, are literature data on a number of membrane and micellar systems. $1 \mathrm{~kJ}=4.184 \mathrm{kcal}$. ${ }^{b}$ A discontinuity in the Arrhenius plot of the excimer to monomer fluorescence intensity ratio is not observed. " Taken from Zachariasse ct al. (1980). ${ }^{d}$ Taken from Zachariasse ot al. (1982).

105 and 44, as expected from the literature value of 90 for the lipid/protein molar ratio of intact SR membranes.

It appears that below $20^{\circ} \mathrm{C}$ the direct surroundings of the $\mathrm{Py}$ (3)Py probe are similar to the environment found for this probe in human erythrocyte ghost membranes and in bilayers of DMPC (Table I). Above $20^{\circ} \mathrm{C}$, the probe environment in the native SR membranes and in the other systems presented in Table I has similarities to that in a micellar solution of $\mathrm{NaDodSO}_{4}$ and to that in the phosphatidylcholine bilayer systems in the fluid phase. That the two systems with lipid/protein molar ratios below 44 do not show a break in the Arrhenius plot of $I^{\prime} / I$ can be related to the fact that for these ratios all of the lipids are thought to be tightly bound to the ATPase molecule, as described above.

From the fact that the discontinuity in the Arrhenius plots disappears when the enzyme is delipidated, it is concluded that the appearance of the discontinuity in the temperature dependence of the membrane fluidity is a characteristic of the lipid portion of the membrane. This would mean that a change in the overall structure of the lipid environment in the SR membrane, not involving a first-order phase transition (Martonosi, 1974), takes place around $20^{\circ} \mathrm{C}$. This change in structure of the lipid portion of the SR membrane is perhaps associated with the reported (Anzai et al., 1978) change in the conformation of the Ca-ATPase molecule at about $20^{\circ} \mathrm{C}$.

Since the temperatures of the discontinuities in the $\mathrm{Ar}$ rhenius plots of $I^{\prime} / I$ (Figure 8 ) have values close to those observed for the breaks in the enzyme activities, as already discussed above, it is suggested that the enzyme activity is modulated by the fluidity of the membrane. Experiments are in progress with a variety of reconstituted systems and with lobster SR membranes, which show a discontinuity in the enzyme activity at a different temperature, $11^{\circ} \mathrm{C}$ (Madeira et al., 1974). These experiments can possibly provide further evidence of these phenomena.

$V$ iscosity of the SR Membrane as a Function of Temperature. Intramolecular excimer formation of dipyrenylpropane was studied in liquid paraffin as a function of temperature (Zachariasse, 1978). In Figure 9, the excimer to monomer fluorescent intensity ratio, $I^{\prime} / I$, obtained at various temperatures has been plotted as a function of $T / \eta$. The viscosity was 

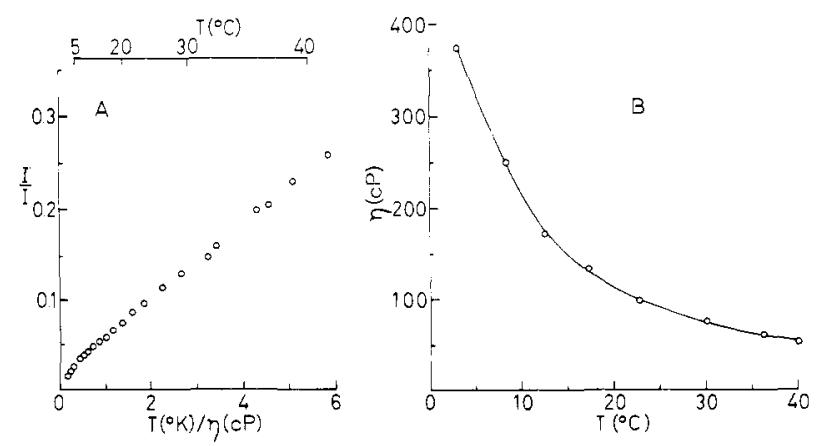

FIGURE 9: Excimer to monomer fluorescence intensity ratios of 1,3-di(1-pyrenyl)propane $\left(5 \times 10^{-7} \mathrm{M}\right)$, dissolved in liquid paraffin, as a function of $T / \eta(\mathrm{A})$. The viscosity was measured at each temperature. (B) Viscosities of sarcoplasmic reticulum membranes, on the basis of this calibration curve.

determined over the same range of temperatures.

The viscosity of the probe environment in the sarcoplasmic reticulum membrane, based on this calibration curve, ranges from 325 to $52 \mathrm{cP}$ over the temperature range from 5 to 40 ${ }^{\circ} \mathrm{C}$. At the physiological temperature $\left(37^{\circ} \mathrm{C}\right)$, a value of 60 $\mathrm{cP}$ was obtained. The present methodology could be used since the fluorescence spectra of the pyrenyl probe are identical in membranes and liquid paraffin.

\section{References}

Anzai, K., Kirino, Y., \& Shimizu, H. (1978) J. Biochem. (Tokyo) 84, 815-821.

Bartlett, G. R. (1959) J. Biol. Chem. 234, 466-468.

Bennett, J. P., McGill, K. A., \& Warren, G. B. (1980) Curr. Top. Membr. Transp. 14, 127-164.

Böttcher, C. J. F., van Gent, C. M., \& Pries, C. (1961) Anal. Chim. Acta 24, 203-204.

Carvalho, A. P., \& Madeira, V. M. C. (1974) in Biomembranes-Lipids, Proteins and Receptors (Burton, R. M., \& Packer, L., Eds.) pp 347-367, BI-Science Publication Division, Webster Groves, MO.

Connors, K. A. (1967) A Textbook of Pharmaceutical Analysis, pp 261-267, Wiley, New York.

Davis, D. G., Inesi, G., \& Gulik-Krzywicki, T. (1976) Biochemistry 15, 1271-1276.

Dean, W. L., \& Suárez, C. P. (1981) Biochemistry 20, 1743-1747.

Emert, J., Behrens, C., \& Goldenberg, M. (1979) J. Am. Chem. Soc. 101, 771-772.

Galla, H. J., \& Sackmann, E. (1974) Biochim. Biophys. Acta 339, 103-115.

Gornall, A. G., Bardawill, C. J., \& David, M. M. (1949) J. Biol. Chem. 177, 751-766.

Hasselbach, W. (1979) Top. Curr. Chem. 78, 1-56.
Heremans, K., \& Wuytack, F. (1980) FEBS Lett. 117, $161-163$.

Hesketh, T. R., Smith, G. A., Houslay, M. D., McGill, K. A., Birdsall, N. J. N., Metcalf, J. C., \& Warren, G. B. (1976) Biochemistry 15, 4145-4151.

Inesi, G., Millmann, M., \& Eletr, S. (1973) J. Mol. Biol. 81, 483-504.

Le Maire, M., Møller, J. V., \& Tanford, C. (1976) Biochemistry 15, 2336-2341.

Lowry, O. H., Rosebrough, N. J., Farr, A. L., \& Randall, R. J. (1951) J. Biol. Chem. 193, 265-275.

Mac Lennan, D. H. (1970) J. Biol. Chem. 245, 4508-4518.

Madeira, V. M. C. (1978) Arch. Biochem. Biophys. 185, 316-325.

Madeira, V. M. C., Antunes-Madeira, M. C., \& Carvalho, A. P. (1974) Biochem. Biophys. Res. Commun. 58, 897-904.

Madeira, V. M. C., \& Antunes-Madeira, M. C. (1976) Cienc. Biol. (Coimbra) 2, 265-291.

Martonosi, A. (1968) J. Biol. Chem. 243, 71-81.

Martonosi, A., Donley, J. R., Pucell, A. G., \& Halpin, R. A. (1971) Arch. Biochem. Biophys. 144, 529-540.

Martonosi, M. A. (1974) FEBS Lett. 47, 327-329.

Meissner, G., Connor, G. E., \& Fleischer, S. (1973) Biochim. Biophys. Acta 298, 246-269.

Melnick, R. L., Haspel, H. C., Goldenberg, M., Greenbaum, L. M., \& Weinstein, S. (1981) Biophys. J. 34, 499-515.

Metcalfe, J. C., Bennett, J. P., Hesketh, T. R., Houslay, M. P., Smith, G. A., \& Warren, G. B. (1976) in The Structural Basis of Membrane Function (Hatefi, Y., \& DjavadiOhaniance, L., Eds.) Academic Press, New York.

Podo, F., \& Blasie, J. K. (1977) Proc. Natl. Acad. Sci. U.S.A. 74, 1032-1036.

Racker, E. (1972) J. Biol. Chem. 247, 8198-8200.

Tada, M., Yamamoto, T., \& Tonomura, J. (1978) Physiol. Rev. 58, 1-79.

Warren, G. B., Toon, P. A., Birdsall, N. J. M., Lee, A. G., \& Metcalfe, J. C. (1974) Proc. Natl. Acad.Sci. U.S.A. 71, 622-626.

Weber, A., Herz, R., \& Reiss, I. (1963) Biochem. Z. 345, 329-369.

Weber, K., \& Osborn, M. (1969) J. Biol. Chem. 244, 4406-4412.

Zachariasse, K. A. (1978) Chem. Phys. Lett. 57, 429-432.

Zachariasse, K. A., Kühnle, W., \& Weller, A. (1978) Chem. Phys. Lett. 59, 375-380.

Zachariasse, K. A., Kühnle, W., \& Weller, A. (1980) Chem. Phys. Lett. 73, 6-11.

Zachariasse, K. A., Vaz, W. L. C., Sotomayor, C., \& Kühnle, W. (1982) Biochim. Biophys. Acta 688, 323-332. 